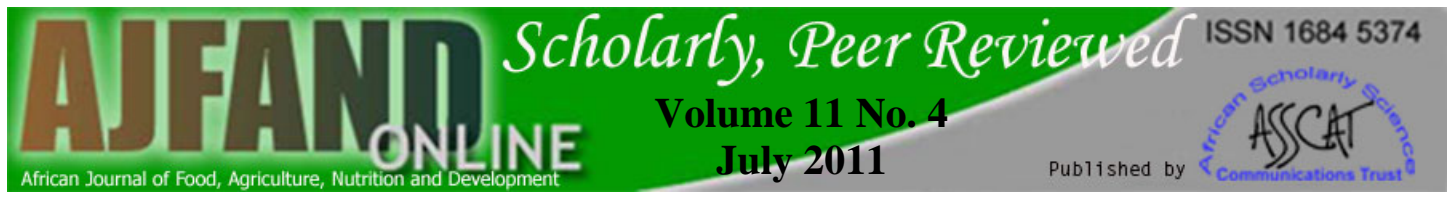

\title{
YOUNG CHILDREN FEEDING AND ZINC LEVELS OF COMPLEMENTARY FOODS IN WESTERN CAMEROON
}

Kana $\mathrm{SMM}^{1}$, Kikafunda $\mathrm{JK}^{2}$, Meli FC ${ }^{3}$, Gouado $\mathrm{I}^{1}$, Zollo $\mathrm{PHA}^{3}$, Oberleas $\mathrm{D}^{4}$ and $\mathrm{E}$ Tetanye ${ }^{5}$

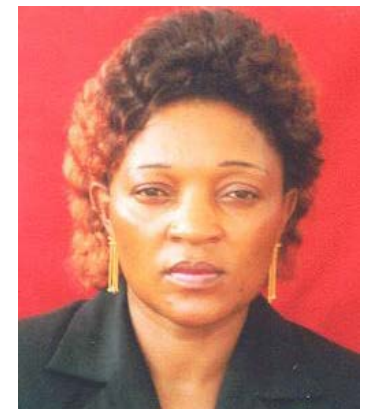

Sop Kana

*Corresponding author email:kanamod@yahoo.com

${ }^{1}$ Department of Biochemistry, University of Douala, Cameroon,

${ }^{2}$ Department of Food Science and Technology, Makerere, University, Uganda

${ }^{3}$ The University of Ngaoundéré, Cameroon

${ }^{4}$ Food and Nutrition, Texas Tech Emeritus, $340488^{\text {th }}$ Street, Lubbock, Texas

${ }^{5}$ Faculty of Medicine and Biomedical Sciences, University of Yaoundé 1, Cameroon 


\section{ABSTRACT}

Malnutrition among young children in Cameroon starts during complementary feeding or the transition period. Last nutritional surveys indicated high prevalence of protein energy malnutrition, iron deficiency anemia and Vitamin A deficiency in children aged 6 to 59 months. No data on appropriate feeding and zinc content in foods are available for this group. The purpose of this work was to study feeding practices, zinc content and intake of complementary foods in the West Province of Cameroon. One hundred and seventy-two mothers (172) selected from Bangang and Bassessa localities helped to identify the recipes used for preparation of complementary foods. A questionnaire helped to identify and report anthropometric measures of children, the main foods given to them, the cooking methods and the frequency of consumption. Eleven common traditional foods used during the complementary feeding period in these localities were chosen after interviewing mothers with babies under 36 months, cooked in triplicate (three different meals per recipe), as described by mothers, and kept at $-20^{\circ} \mathrm{C}$ for the analyses of their zinc levels and its intakes. The quantities of food eaten by the children were measured by differences of weights of meals at the beginning and at the end of each child feeding. Maternal milk was consumed by $98.8 \%$ of babies.. Early (43\%) and late (49\%) complementary feeding were both observed. Total zinc levels were obtained by Atomic Absorption Spectrophotometry and ranged between $0.66 \pm 0.05 \mathrm{mg} / 100 \mathrm{~g}$ DW in boiled sweet potato wheneaten with avocado and $2.30 \pm 0.34 \mathrm{mg} / 100 \mathrm{~g}$ DW in maize paste (MP) with okra and fish. Zinc intakes estimated from quantities of food consumed comprised between $0.49 \pm 0.04 \mathrm{mg} / 100 \mathrm{~g}$ DW in ripe banana to $2.91 \pm 0.27$ $\mathrm{mg} / 100 \mathrm{~g}$ DW in Irish potato cooked with eggs and fresh fish. The maximum combination in three meals could cover only $31 \%$ to $67 \%$ of the $3 \mathrm{mg}$ and $6 \mathrm{mg}$ recommended daily zinc intakes for children less than 6 months and between 6 and 12 months, respectively. The foods were mainly from vegetal sources and may contain phytates that highly reduce zinc intakes and reabsorption of resecrated zinc in the gastro-intestinal tract. Zinc nutrition is still not well addressed as a public health problem in Cameroon where vitamin A deficiency remains endemic with high prevalences in some regions.

Key words: Zinc levels, intakes, complementary foods 


\section{INTRODUCTION}

The complementary feeding period is a transition period between 6 and 24 months, during which children gradually eat other foods to complement milk that can longer cover their nutritional requirements. It is the time when children are vulnerable to malnutrition because of inappropriate food habits and practices. Iron deficiency anemia, vitamin A deficiency and protein-energy malnutrition were reported to be responsible for about $60 \%$ of deaths[1]. Many studies indicate zinc deficiencies, but data on zinc content and the real extent of zinc deficiency are still scarce [2]. Zinc deficiency today is one of the most prevalent micronutrient deficiencies worldwide; among the five most prevalent mineral deficiencies (zinc, iron, copper, magnesium and chromium). The importance of zinc is not as well recognized because it exhibits few clinical symptoms and lacks overt indicators and techniques for clinical assessment [3]. More than 300 different enzymes require zinc for their activities in cell division and metabolism in human being. It is essential for many diverse functions including growth and development, reproduction, immune, secretory functions, antioxidant protection, and stabilization of membranes [4, 5]. Zinc is also involved in vitamin A assimilation, psycho-neurological, epidermal, gastro-intestinal health and is linked to "adolescent nutritional dwarfism syndrome” [5].

Recent studies have reported the role of zinc in the assimilation of vitamin A and antidepressants, for example magnesium. Like other types of malnutrition and micronutrient deficiencies, the prevalence of zinc deficiency is higher in developing countries. Precise data about the incidence of clinical zinc deficiency in infants and children are not yet established, although indirect evidence suggests the problem is common worldwide. The RDA for zinc is about $5 \mathrm{mg}$ for infants and $8 \mathrm{mg}$ for children aged $1-4$ years. The etiology of zinc deficiency may be dietary, physiologic or genetic. Nutritional zinc deficiency may arise from inadequate intake or poor retention associated with phytates, which is a natural constituent of plant seeds and food grains [4]. Nutritional zinc deficiency seldom occurs in the absence of phytate. The intimate relationship between dietary phytate intake and zinc homeostasis compromise RDA estimations for zinc, because RDAs are based on phytate-free dietary estimates [2]. The most vulnerable groups are infants and young children. Surveys in Cameroun indicated high prevalence of more identifiable iron, vitamin A and protein-energy malnutrition in these groups as a sign of overall poor nutritional situation of several micronutrients $[6,7,8]$. Previous studies on nutrient content have shown low levels of nutrients in traditional complementary foods from rural zones, indicating inadequate supply of these nutrients to meet the body's needs for protein, iron, magnesium, and particularly zinc [9].

In Cameroun, however, zinc deficiency has not been considered as an existing micronutrient deficiency of public health importance like iodine, iron and vitamin A deficiencies. Using two indicators comprising childhood stunting or underweight and the mean daily per capita needs for zinc in the national food supply, Cameroun was classified like other Central African countries as a country with high risk of zinc deficiency by WHO [10]. Caulfield et al.[11]reported a lack of data on complementary feeding in Cameroun when working on interventions to improve

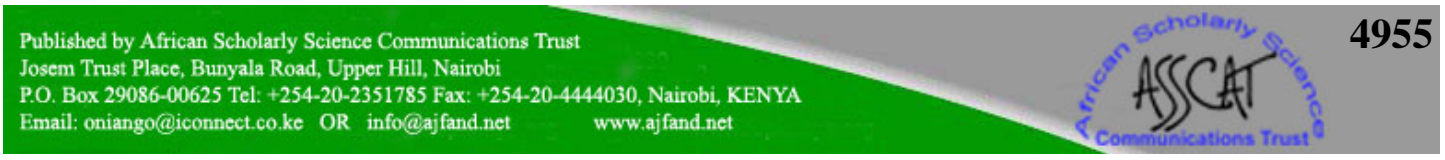




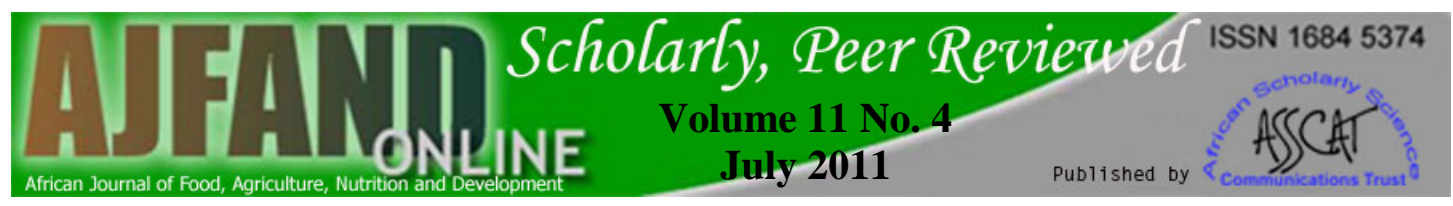

intake of complementary foods by infants 6 to 12 months of age in developing countries in the late 1990s. Few data exist on complementary foods in Africa [12] and in Cameroun $[9,13,14,15]$. This preliminary study was aimed at screening the best dietary sources of zinc among the most commonly used complementary foods in two rural areas of Cameroun. The main objective of this work was to determine dietary zinc content and intakes from the most commonly used complementary foods in two rural localities in the West province of Cameroun.

\section{MATERIALS AND METHODS}

The study was carried out from March to April 2008.

\section{MATERIALS}

A questionnaire was used to survey mothers and caregivers or caretakers in order to record the health histories, anthropometric indices, food frequency and the 24 hour recall for infant feeding and practices during the complementary feeding period.

The test meals were selected from 24 hour recall, and focus group discussions involving one hundred and seventy two (172) mothers and caregivers were carried out in Bangang and Bassessa, two rural localities in the West province of Cameroun. Questionnaires helped to report frequently eaten complementary foods and practices during complementary feeding period. The specific Focus Groups Discussions were organized with men and women to understand why and how children are fed. This province and the localities were chosen because the national surveys (2001 and 2004) showed lower prevalence of overall malnutrition in that part of the country. It was important to understand how these children were fed in order to popularise and extend the findings to help mothers in the most affected provinces (North, East and big towns). The selection of sites also allowed the study of traditional and local complementary food patterns. Eleven samples comprising Irish potato gruels, corn gruels and meals eaten with vegetable sauces, ripe banana and roasted Irish potatoes were chosen for their frequency of consumption. They were cooked in triplicate (three different types of cooking for the same recipe) by boiling, in the laboratory kitchen, in traditional aluminium pots, according to the description of mothers and with their help. They were then freeze-dried and kept at $-20{ }^{\circ} \mathrm{C}$ for chemical analyses. Ripe banana in rural Western Province of Cameroon is considered a complementary food and sometimes used monotonously to feed babies the whole day. A mother could easily leave a baby with five ripe bananas as the child's only food for the whole day. This is why these ripe bananas are considered as complementary food. Children are sometimes given family meals, but current interest is in foods known as complementary foods. Six (6) of these recipes were selected because of their little variability and their wide use in many families as complementary foods. The meals were reproduced in triplicate as indicated by the mothers with usual ingredients (table 1). 


\section{METHODS}

\section{Dry weight}

Dry weight (DW) was determined after drying the samples in the oven at $105^{\circ} \mathrm{C}$ to constant weight using standard AOAC methods [16].

\section{Total zinc contents}

Zinc contents were measured by Flame Atomic Absorption Spectrometry (Spectrophotometer: ACTIUNICAM 929 series GE 4999190) using the method described by Clegg et al. [17].

\section{Zinc intake estimates}

Zinc intakes as a function of age were deduced from average consumption of single meals or daily diet and the zinc content in foods. The contents were measured by differences of weight of the meals before and after each feeding and on $24 \mathrm{hr}$ record. Additional items were estimated (some small portions of family foods) based on size [4]. The average percentages were calculated considering the approximate weight based on Recommended Daily Allowances (RDA) of FAO/IAEA/WHO in 1996, which is 3-4 mg for infants aged between 0 and 3 months and 5-6 mg for those aged 6 months and beyond.

\section{Statistical analyses}

Statistical analyses of the results were performed according to Wilkinson 2.0 [18]. The statistical analysis of data was done by one way Analysis of Variance (ANOVA) using $5 \%$ level of significance. This enabled the researchers to assess if there were differences between zinc levels and intakes based on the nature of ingredients used for preparing the dishes studied. The Duncan multiple range statistical tests were used to compare means $(\mathrm{p} \leq 0.5)$.

\section{RESULTS}

\section{Breastfeeding factor}

Information on breastfeeding, complementary foods and practices from one hundred and seventy two (172) mothers and caretakers were recorded. Maternal breastfeeding comprised also breast milk and water, but no semi solid or solid food feeding was practiced at $98.8 \%$.

It was observed that most babies were exclusively breastfed. This is linked to habit and to the high cost of manufactured milk for families living in rural areas. The two infants who received mixed breastfeeding were twins. In this study, mixed breastfeeding was considered as taking breast milk along with artificial milk.

\section{Introduction of other foods}

It was noted that $43 \%$ of children started complementary feeding before the age of 6 months, whereas, $49 \%$ of them started it after the age of 6 months (table 2).Only 8\% of infants started complementary feeding at 6 months as recommended WHO[10]. These findings indicate a crucial problem of complementary feeding which is not

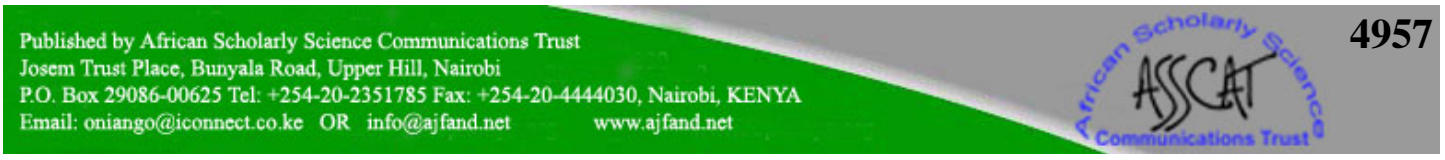




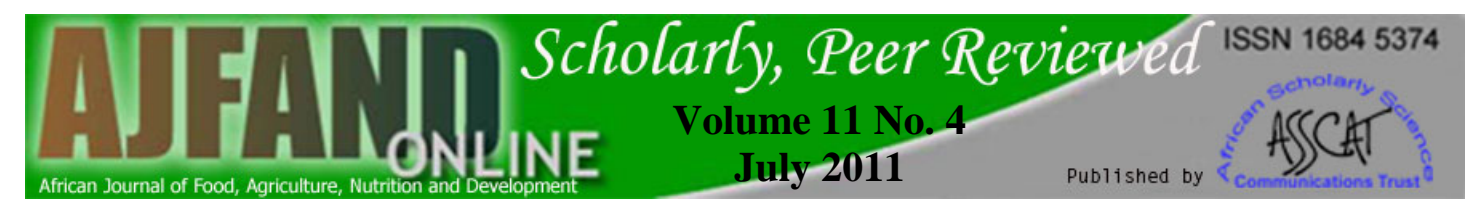

optimal, and which is either too late or too early. The main foods were: Corn Gruel(CG); Corn gruel + fresh milk (CGM), Corn gruel + fresh milk + lime juice(CGML), Irish potato with eggs and fresh fish (PEF), Simple Irish potato (P), Roasted Irish Potato (RP), Irish potato pounded with pre-boiled red beans(PB), Maize paste(MP), Maize paste and okro sauce (MPO), Sweet potato and Avocado(SPA) and Ripe Banana (RB).It was noted that complementary foods were cooked once a day and given monotonously with poor hygienic care.

\section{Zinc content and intakes from daily diets}

The results of chemical analyses and zinc intakes are presented in mg/100 g dry weight (DW) in the table 3. Statistical analyses are incorporated in form of letters. Values in the same column with the same superscripts are not significantly different at $\mathrm{p} \leq 0.05$ and the values are given as mean \pm Standard Deviation.

Zinc levels ranged between $0.66 \pm 0.05 \mathrm{mg} / 100 \mathrm{~g}$ DW in boiled sweet potato eaten with avocado and $2.30 \pm 0.34 \mathrm{mg} / 100 \mathrm{~g}$ DW in maize paste with Okra sauce. Even at the highest levels, these foods could not fulfil the daily zinc needs of the babies, no matter the age (table 2). Figure 1 shows that children less than 6 months had low dietary intake of zinc compared to those aged more than 6 months when referred to the recommended daily allowances.

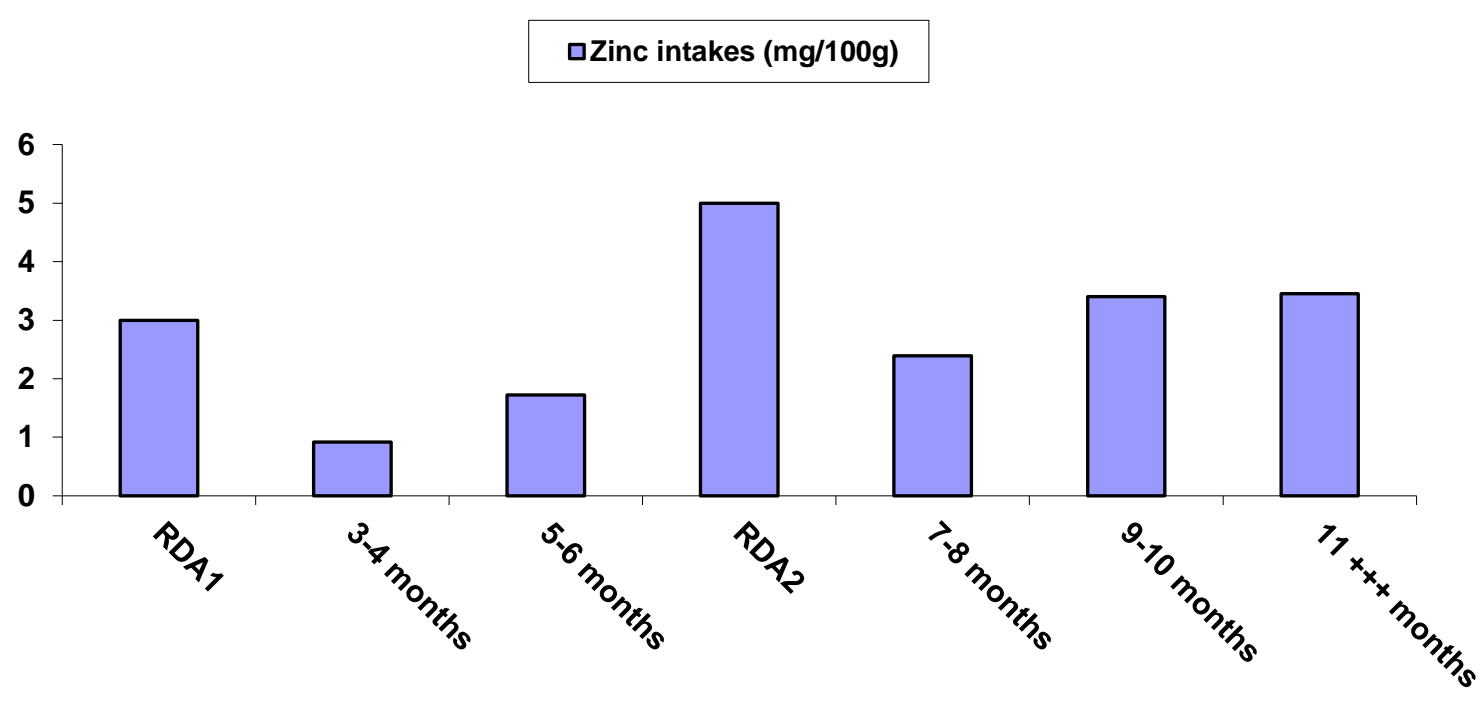

Figure 1: Zinc intakes per age compared to Recommended Daily Zinc Intakes RDAs

Zinc intakes estimated from quantities of food consumed ranged between $0.49 \pm 0.04$ $\mathrm{mg} / 100 \mathrm{~g}$ DW in ripe banana and $2.91 \pm 0.27 \mathrm{mg} / 100 \mathrm{~g} \mathrm{DW}$ in Irish potato cooked with eggs and fresh fish. The maximum combination in three meals contributed to cover only $31 \%$ to $67 \%$ of $3 \mathrm{mg}$ and $6 \mathrm{mg}$ recommended daily zinc intakes of children below 6 months and those between 6 and 12 months, respectively. Estimation from 


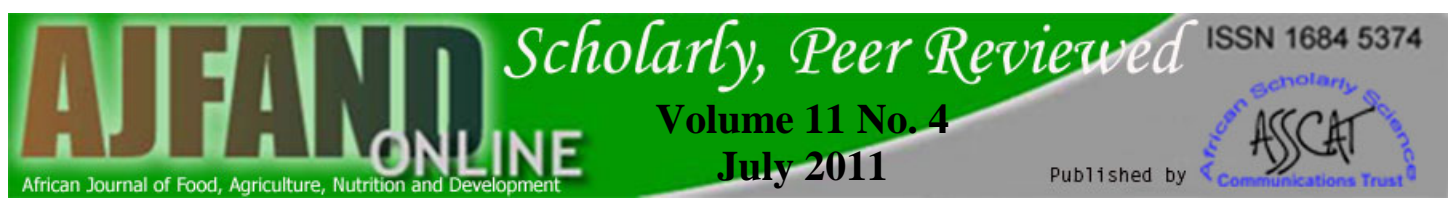

daily diet zinc contents gave zinc intakes as a function of age, ranged from $31 \%$ between 3 and 4 months to 67 \%at 11 months and beyond (table 4).

\section{DISCUSSION}

\section{Introduction of complementary foods}

The fact that $43 \%$ of children started complementary feeding at less than 6 months and $49 \%$ started above 6 months was highly inappropriate, exposing children to malnutrition and poor growth by early and late introduction to complementary feeding. Only $8 \%$ of infants started complementary feeding at 6 months, the recommended optimal age of introduction of complementary foods by suggested by WHO in 2006for healthy mothers and healthy born babies. These observations revealed that complementary feeding practices were not optimal [10].The observed reduced growth rates observed on health report cards were linked with improper complementary foods, poor feeding practices expressed by early and late introduction of complementary foods, leaving young babies during long periods without breastfeeding due to farming and market activities, lack of time and the heavy schedules of mothers and caregivers who have many daily activities [19]. The knowledge of exclusive breastfeeding, meaning that no other liquid, not even water is added was difficult to understand and to be applied by mothers. Some of the mothers gave sugared water to children along with breast milk, reducing the optimal intake of breast milk which contains high available micronutrients. However, the use of manufactured milk was not frequent because of the poor buying power of the mothers.

\section{Zinc levels and intakes}

Zinc levels in all the tested meals were low compared to those reported in leafy vegetable sauces (5.4 to $9.1 \mathrm{mg} / 100 \mathrm{~g} \mathrm{DW}$ ) and in some traditional meals (1.23 to $5.70 \mathrm{mg} / 100 \mathrm{~g}$ MS) in Cameroon[12,13] and in Nigerian dishes [20]. This may be linked directly to the composition of meals, poor in animal foods and fruits. Foods from animal sources are rich in bio-available minerals and as they are usually incorporated in proteins. They should be eaten regularly with vegetal foods in which minerals bioavailability is affected by the presence of many absorption inhibitors (phytates and tannins, for example).This bioavailability is poor, but it uptake can be positively or negatively influenced by other factors of the meals (activators and inhibitors). Fruits are not rich in minerals, but can enhance mineral absorption because of their high content in organic acids that are activators of mineral absorption. Micronutrients whose absorption is influenced by the meal composition are bivalent cations (non heme iron, zinc, calcium and magnesium) [21].

Early introduction of complementary foods impairs optimal intakes of maternal zinc. Zinc content in breast milk is not high. However, it is well absorbed by babies, and this high bioavailability can be affected by poor complementary foods. Low levels and intakes of zinc studied in complementary foods raised a serious problem of zinc deficiency as a public health problem not yet addressed in Cameroon. The content of zinc in these meals was low compared to recommended dietary zinc allowances from WHO [21], and to those reported by Koenig and co-workers [22] on the average concentration in eight German hospital diets, where zinc levels varied between 7.2

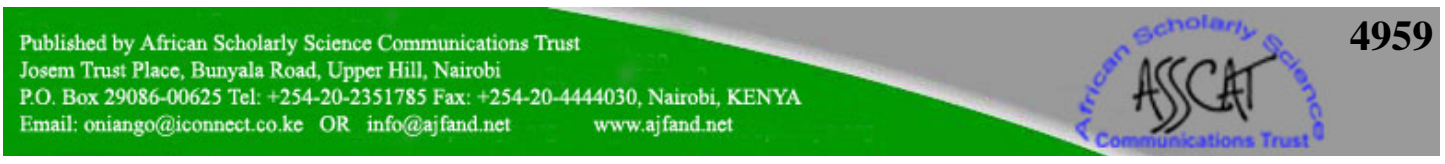




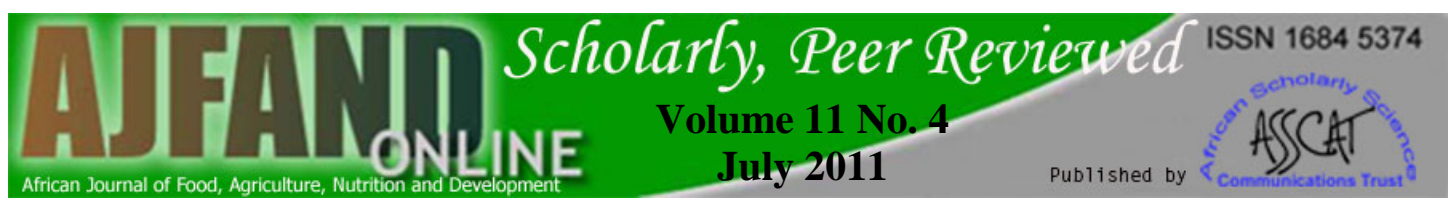

and $17.6 \mathrm{mg} / \mathrm{d}$. These diets were used in the hospitals with no specification on the nature of beneficiaries [23].

This content of zinc could only cover from 31 to $67 \%$ of the recommended daily allowances (RDA). Cameroon was one of the countries with high prevalence of zinc deficiency (50 \%) as reported by Rivera and co-workers in a study using two indirect indicators. However, no particular programme, policy and research on zinc are given any priority in Cameroon.

The low coverage of daily zinc needs raised a serious problem of zinc deficiency within the children of Cameroon. Before six (6) months, children were given only maize gruels without any enrichment. This may explain why zinc levels and intakes were very low before 6 months. These complementary foods were mostly of vegetable origin and were classified as responsible for poor zinc homeostasis [2]. This is because plant seeds, particularly legumes, contain high levels of phytates. They are natural constituents of seeds and grains, and are inhibitors of zinc absorption and negatively influence its homeostasis. They constitute about $60-70 \%$ of total phosphorus in mature seeds with a chemical nature that connotes high potential for cations, particularly zinc, complexes. Elevated dietary calcium in the presence of phytate also synergistically binds zinc and calcium more tightly, making zinc a most vulnerable micronutrient leading to its non availability. [2]. Oberleas and Harland in 2003, also reported that, $36 \%$ of infants and $74 \%$ of children of 3 to 24 months of age failed to get 2/3 of the estimated zinc RDA [3]. During the survey, it was noticed that fruit and vegetables were scarcely consumed. This was linked to ignorance and poor fruit cultivation in these localities. Some fruits were available (mangoes, pear, guava and oranges), but only seasonally, making it difficult to develop good strategies for children feeding in all the seasons. Beans were widely available and were usually mixed with Irish potatoes as whole grains.

Considering the levels of the consumption of whole grains and legumes throughout the world, mild to moderate zinc deficiency may be more common worldwide than previously suspected, especially in Cameroon and in many sub-Saharan African countries. Very low animal product consumption was noted, probably due limited financial resources and lack of sufficient knowledge to include small livestock in familial agricultural activities. The diets were monotonous and mainly based on tubers, cereals and legumes (beans) that were great sources of phytates. Phytates are natural components of most diets of the world's population that inhibit zinc absorption and reabsorption [3]. Zinc is secreted via the pancreas into the duodenum in large quantities. A large amount of this zinc is vulnerable to phytate complexation in the duodenum and upper jejunum, thus not reabsorbed if there is a high concentration of phytate near the absorption sites [4]. This intimate relationship between zinc and phytate led Oberleas and Harland to develop an HPLC method for analytical determination of phytate content of foods and its validation to predict zinc deficiency using a mathematical formula [3]. Early introduction of complementary food in rural areas is dangerous for children health because of poor hygienic conditions and the fact that phytate not only impairs the amount of zinc that a child can absorb, but can also inhibit the reabsorption of rescrated zinc [10, 21].

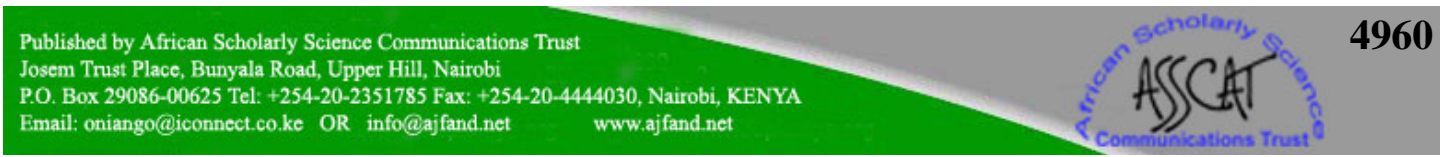


Cameroon diets were mostly from vegetable sources and were also sources of phytate that may affect the bioavailability of zinc as well as its homeostasis. The alternative to improve zinc homeostasis is the addition of rich sources of zinc (see foods) meals or the introduction of microbial phytases that reduce the phytate component in the gastrointestinal tract [3]. Best zinc sources are animal foods like meat, liver, eggs and seafood and some vegetables [24]. Yonekura and Suzuki have reported that some polysaccharides could also improve zinc absorption of rats fed on a phytic acidcontaining diet [25]. The slightly high content of zinc in the Irish potatoes cooked with egg or fish may be linked to the presence of egg yolks and fish in recipes. Other studies reported improved quality of nutrient with fermentation and germination that stimulate phytases which in turn hydrolyse phytates, reducing their cation binding effect. A microbial phytase suitable for human consumption that could constitute an alternative is not yet commercially available [26].

The content of zinc in this study was higher than those reported for other zones of Cameroun. This may explain why the Western Province of Cameroun appears to have less prevalence of micronutrient deficiencies (iron and vitamin A), as reported in many surveys compared to other regions [12]. The specificity of the region is that, maize gruel is not the main semi- solid food introduced during the transition period. The most frequent complementary food is Irish potatoes and leafy vegetable sauces as eaten in households with maize paste and ripe banana. The majority of people in this region are farmers; thus mothers and caretakers lack time to prepare maize gruel that is time consuming and may be costly, as the sugar must be purchased. The fact that maize gruel Is not the main complementary food appears to be helpful for optimal complementary feeding using Irish potatoes and ripe bananas and soft family foods. Irish potatoes which are available can be easily boiled or roasted, and mashed with salt and red oil by every mother and caretaker. Maize paste with okra is a household meal and is more frequently cooked when there is a baby in the family because it is soft and can thus be adapted to feed children. Ripe banana is easily given to the baby using a teaspoon. But still, growth faltering was observed between 4-6 months like in other studies [14, 27]. This growth faltering in children becomes apparent as early as at three months of age; with the steepest decline in growth occurring between three and 12 months of age, which was also reported by Nnyepi et al. [28]. Documented studies have shown the importance of zinc in protein synthesis, cell development and linear growth in children, hence deficiency is associated with growth failure [21].

\section{CONCLUSION}

The aim of this work was to study feeding practices, complementary foods and their zinc content and intakes in two localities of the West Province of Cameroon. Poor complementary feeding practices were observed; there were neither guidelines nor timing and appropriate knowledge related to infant feeding and cares. Complementary foods were monotonous and either introduced very early or very late, compromising young children's nutrition and growth. The main complementary food was Irish potatoes, cooked alone or blended, denser in nutriment than maize gruels, with lower water content than the latter. Zinc content and intakes in studied complementary foods

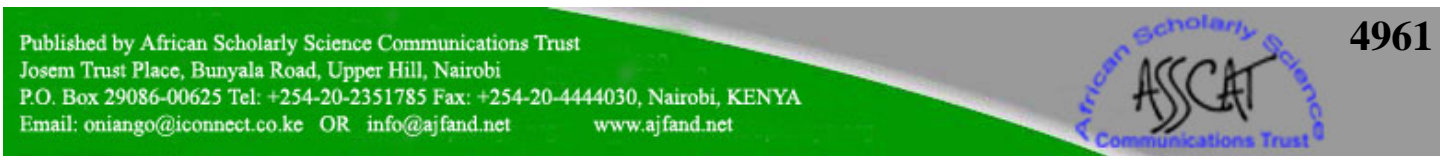


was very low, mostly in maize gruels, and could not cover recommended daily intakes. Because of the poor consumption of animal products, probably linked to poverty, these low zinc levels and intakes may induce zinc deficiency and growth failure in young children of those localities. It is recommended that mothers and caretakers start complementary feeding at six (6) months for children born of healthy mothers. They should introduce fruits, add animal foods, and lime juice to gruels to improve not only the zinc, but also other micronutrient levels and intakes. They could ferment maize to improve digestibility and hygienic quality of complementary foods, and use germinated legumes to reduce phytates, blend maize gruels or Irish potatoes purées with eggs, groundnut and soybean in order to increase energy, proteins and micronutrients densities of traditional complementary foods. Finally, it can be concluded that low prevalences in malnutrition in the studied localities were not linked to special knowledge, but to food habits. Irish potatoes, dense in nutrients are widely used, compared to other regions, where the main complementary food is thick maize gruel, poor in nutrients when not enriched.

\section{ACKNOWLEDGMENT}

We are grateful to the mothers and caretakers who actively participated in this work. 


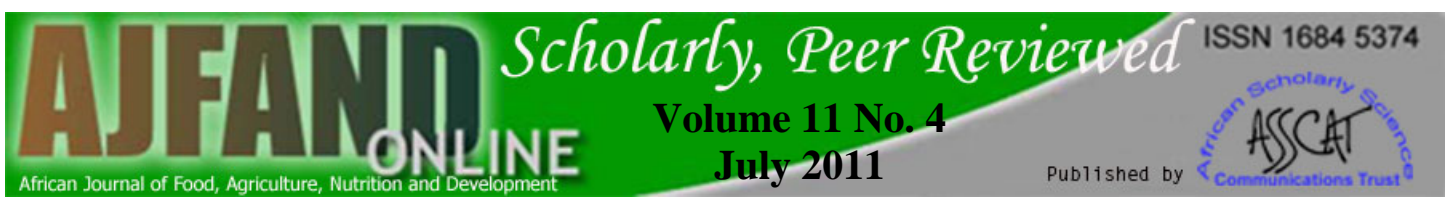

Table 1: Composition of tested meals

\begin{tabular}{|c|c|c|c|c|c|c|c|c|c|c|c|}
\hline$\frac{\text { Recipes }}{\text { Ingredients }}$ & $\begin{array}{l}\mathbf{C G} \\
+\mathbf{M}\end{array}$ & $\begin{array}{l}\mathbf{C G} \\
+\mathrm{M} \\
\end{array}$ & $\begin{array}{l}\text { CG+ } \\
\mathbf{M}+\mathbf{L}\end{array}$ & $\begin{array}{l}\text { PE } \\
\text { F }\end{array}$ & $\mathbf{P}$ & $\mathbf{R P}$ & $\begin{array}{l}\text { P+ } \\
\text { B }\end{array}$ & MP & $\begin{array}{l}\text { MP+ } \\
\text { Okra }\end{array}$ & $\begin{array}{l}\text { SP+ } \\
\text { A }\end{array}$ & R B \\
\hline Fermented corn dough (g) & 100 & 100 & 100 & & & & & & & & \\
\hline Fresh milk (ml) & & 30 & 30 & & & & & & & & \\
\hline Sugar (g) & 20 & 20 & 20 & & & & & & & & \\
\hline Water $(\mathrm{ml})$ & 600 & 600 & 600 & + & + & & + & & & & \\
\hline Lime juice(ml) & & & 20 & & & & & & & & \\
\hline Irish potato (g) & & & & 314 & 300 & 200 & 450 & & & & \\
\hline Tomatoes (g) & & & & 107 & & & & & & & \\
\hline Maize paste (g) & & & & & & & & 100 & 100 & & \\
\hline Okra sauce (g) & & & & & & & & & 100 & & \\
\hline Boiled S Potato (g) & & & & & & & & & & 100 & \\
\hline Avocado (g) & & & & & & & & & & 100 & \\
\hline Fresh fish (g) & & & & 47 & & & & & & & \\
\hline Boiled red beans(g) & & & & & & & & & & & \\
\hline Onion(g) & & & & 33 & & & & & & & \\
\hline Egg (g) & & & & 55 & & & & & & & \\
\hline Palm oil(g) & & & & 30 & 30 & + & 35 & & & & \\
\hline Salt (g) & & & & + & + & + & + & & & & \\
\hline Ripe banana (g) & & & & & & & & & & & 100 \\
\hline \multicolumn{12}{|l|}{ +: $\quad$ added in small quantities; } \\
\hline \multicolumn{12}{|l|}{ CG: Corn gruel; } \\
\hline \multicolumn{12}{|c|}{ CG + M: Corn gruel + fresh milk; } \\
\hline \multicolumn{12}{|c|}{$\mathbf{C G}+\mathbf{M}+\mathbf{L}: \quad$ Corn gruel + fresh milk + lime juice; } \\
\hline \multicolumn{12}{|c|}{ PEF: Irish potato with eggs and fresh fish; } \\
\hline \multicolumn{12}{|l|}{ P: Simple Irish potato; } \\
\hline \multicolumn{12}{|l|}{ RP: $\quad$ Roasted Irish Potato; } \\
\hline \multicolumn{12}{|c|}{$\mathbf{P}+\mathbf{B}$ : Irish potato pounded with pre-boiled red beans; } \\
\hline \multicolumn{12}{|l|}{ MP: Maize paste; } \\
\hline \multicolumn{12}{|c|}{ MP+Okra: $\quad$ Maize paste and okra sauce; } \\
\hline SP+A: Sweet potato and A & vocade & & & & & & & & & & \\
\hline R B: $\quad$ Ripe Banana. & & & & & & & & & & & \\
\hline
\end{tabular}




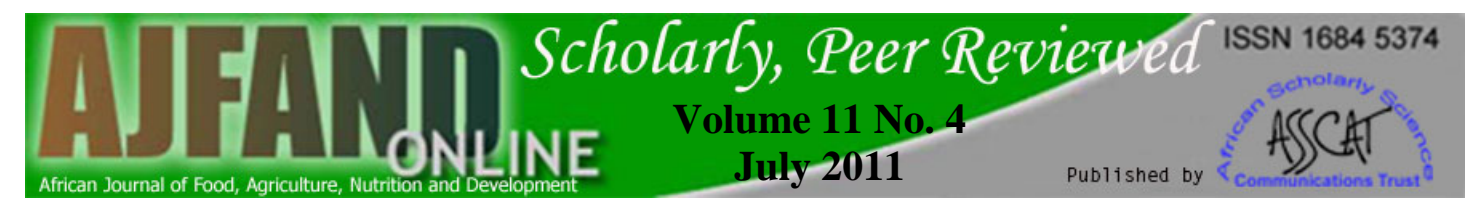

Table 2:Introduction of complementary foods

\begin{tabular}{lllllllllll}
\hline $\begin{array}{l}\text { Age } \\
\text { (months) }\end{array}$ & $\mathbf{1 - 2}$ & $\mathbf{3}$ & $\mathbf{4 - 5}$ & $\mathbf{6}$ & $\mathbf{7 - 8}$ & $\mathbf{9 - 1 0}$ & $\begin{array}{l}\mathbf{1 1 -} \\
\mathbf{1 2}\end{array}$ & $\mathbf{1 3 - 1 4}$ & $\begin{array}{l}\mathbf{1 5}- \\
\mathbf{1 7}\end{array}$ & $\mathbf{1 8}$ \\
$\begin{array}{l}\text { Number } \\
\text { \% }\end{array}$ & 18 & 25 & 30 & 15 & 19 & 18 & 15 & 10 & 12 & 11 \\
\hline
\end{tabular}

Table 3: Dry weight, zinc content and intakes from meals in $\mathbf{m g} / 100 \mathrm{~g}$ Dry Weight (DW)

\begin{tabular}{llll}
\hline Samples & $\begin{array}{l}\text { Dry weight } \\
\text { (\% FM) }\end{array}$ & $\begin{array}{c}\text { Zinc contents } \\
(\mathbf{m g} / \mathbf{1 0 0} \mathbf{g ~ D W})\end{array}$ & $\begin{array}{l}\text { Zinc intakes } \\
\mathbf{( m g / 1 0 0 ~ g ~ D W ) ~}\end{array}$ \\
PEF (Irish patato+ egg+fish) & $29.62 \pm 2.17^{\mathrm{b}}$ & $2.18 \pm 0.15^{\mathrm{c}}$ & $2.91 \pm 0.27^{\mathrm{c}}$ \\
P (Simple Irish potato) & $25.88 \pm 2.2^{\mathrm{ab}}$ & $1.77 \pm 0.21^{\mathrm{b}}$ & $2.03 \pm 0.36^{\mathrm{bc}}$ \\
PB (Potato+red beans) & $31.01 \pm 1.99^{\mathrm{bc}}$ & $1.83 \pm 0.21^{\mathrm{bc}}$ & $1.87 \pm 0.32^{\mathrm{b}}$ \\
Roasted Irish potato & $36.23 \pm 2.4^{\mathrm{c}}$ & $1.80 \pm 0.30^{\mathrm{b}}$ & $2.65 \pm 0.41^{\mathrm{c}}$ \\
CG : Corn & $14.30 \pm 2.37^{\mathrm{a}}$ & $1.23 \pm 0.10^{\mathrm{ab}}$ & $1.34 \pm 0.08^{\mathrm{ab}}$ \\
CG + M : & $14.83 \pm 1.74^{\mathrm{a}}$ & $1.14 \pm 0.14^{\mathrm{ab}}$ & $1.23 \pm 0.15^{\mathrm{ab}}$ \\
CG + M + L : & $15.13 \pm 1.74^{\mathrm{a}}$ & $1.10 \pm 0.14^{\mathrm{ab}}$ & $1.43 \pm 0.15^{\mathrm{ab}}$ \\
Maize paste (MP) & $33.11 \pm 2.55^{\mathrm{c}}$ & $0.85 \pm 0.10^{\mathrm{a}}$ & $1.42 \pm 0.13^{\mathrm{b}}$ \\
MP + Okra & $25.54 \pm 3.46^{\mathrm{ab}}$ & $2.30 \pm 0.34^{\mathrm{c}}$ & $1.86 \pm 0.11^{\mathrm{b}}$ \\
Sweet potato + Avocado & $29.67 \pm 0.31^{\mathrm{b}}$ & $0.66 \pm 0.05^{\mathrm{a}}$ & $0.50 \pm 0.04^{\mathrm{a}}$ \\
Banana & $24.97 \pm 1.25^{\mathrm{ab}}$ & $0.88 \pm 0.19^{\mathrm{a}}$ & $0.49 \pm 0.03^{\mathrm{a}}$ \\
\hline
\end{tabular}

FM: Fresh Matter

DW: Dry Weight

Values in the same column with the same superscripts are not significantly different at $p \leq 0.05$, the values are given as mean \pm Standard Deviation (SD).

Table 4: Average zinc intakes and RDA coverage

\begin{tabular}{llllll}
\hline Age (Months) & $\mathbf{3 - 4}$ & $\mathbf{5 - 6}$ & $\mathbf{7 - 8}$ & $\mathbf{9 - 1 0}$ & $\mathbf{1 1}$ and beyond \\
Zinc intakes (G) & 0.92 & 1.72 & 2.39 & 3.2 & 3.35 \\
$\begin{array}{l}\text { Percentage of Coverage } \\
\text { (\%) }\end{array}$ & 31 & 36 & 48 & 62 & 67
\end{tabular}




\section{REFERENCES}

1. Nowack G, Szewczyk B, Polszak E, Librowski T, Opoka W and A Pilc Zinc and magnesium as natural antidepressants: basic and clinical data: Macro, Micro and Trace Elements, $22^{\text {nd }}$ Workshop $24^{\text {th }}-25^{\text {th }}$ September 2004, JENA, GERMANY. 2004: 1406-1410.

2. Oberleas D A new perspective of trace element deficiencies. Trace Elements in Medicine 2003; 1: 3-8.

3. Oberleas D and BF Harland HPLC method for phytates, its validation and application to zinc deficiency diagnosis: Macro, Micro and Trace Elements, 22. Workshop $24^{\text {th }}-25^{\text {th }}$ September 2004, JENA, GERMANY.2004: 19-24.

4. Gibson R Principles of Nutritional Assessment. New York Oxford University press $1990:$ 542-552.

5. Suslikov WL and LM Karzakova Native zinc deficiency and immunoreactivity: Macro, Micro and Trace Elements, 22. Workshop $24^{\text {th }}-25^{\text {th }}$ September 2004, JENA, GERMANY.2004: 1663-1668.

6. Mbofung CMFEffect of preparation methods on the in-vitro bioavailability of iron from a local based weaning food. Nutrient availability: chemical and biochemical aspects. (Southgate, D.A.T., Johnson, I.J., and Fenwick, J.R. eds.) Royal Society of Chemistry, Special publ.1988; 72: 182-184.

7. Lowe JC, Nestel $\mathbf{P}$ and PO Rustein Nutrition et santé des jeunes enfants au Cameroun. Résultats de l'enquête Démographique et de Santé au Cameroun en 1991. Macro International Inc. Collumbia, Maryland USA. 1993: 13-25.

8. RC. (République du Cameroun) Enquête National sur la carence en vitamine A et l’Anémie au Cameroun de Septembre-Octobre 2000. 2001:1-38

9. Kana-Sop MM, AmvamZollo PH and $\mathbf{F}$ Ndifor Iron bioavailability in Cameroon weaning foods and the influence of the diet composition. African $J$. Food, Agric., Nutr. Develop. 2004; 4(1):1-17.

10. WHOInfant and young child nutrition: quadrennial report Report by the Secretariat, Provisional Agenda Item 11.8 4 May 2006, 7 p

11. Caulfield, LE, Huffman, SL and EG Piwoz Interventions to improve intake of complementary foods by infants 6 to 12 months of age in developing countries: Impact on growth and on the prevalence and potential contribution to child survival. Food Nutr. Bull. 1999; 20 (2): 183-200. 


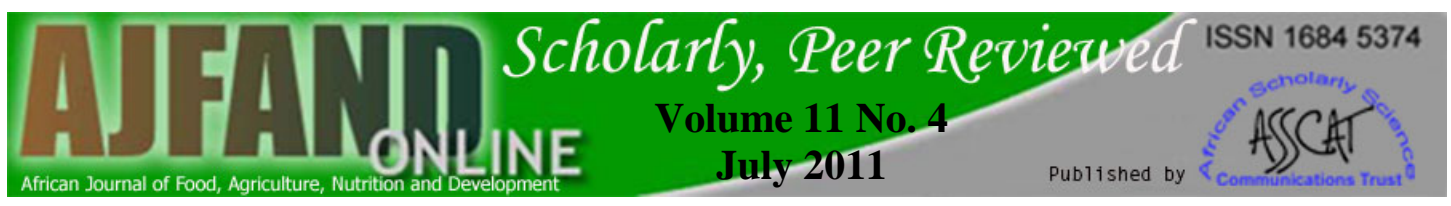

12. Kikafunda JK, Walker AF, Allan EF and JK Tumwine Effect of zinc supplementation on growth and body composition of Ugandan preschool children: a randomised, controlled intervention trial. Am. J. Clin. Nutr.1998; 68:1261-6.

13. Fokou E Contribution à la Valorisation des Aliments Locaux : Etude Biochimique " in vitro » et "in vivo » de quelques éléments nutritifs essentiels des légumes feuilles consommées au Cameroun. Thèse de Doctorat de $3^{\text {ème }}$ cycle. Université de Yaoundé, Faculty of Science 1988: 85-96.

14. Teugwa $\mathbf{C}$ Etude nutritive des plats traditionnels consommés dans une zone rurale de l'Extrême- Nord Cameroun. Leur influence sur quelques paramètres biochimiques sériques. Thèse de Doctorat de $3^{\text {ème }}$ cycle de Biochimie, Université de Yaoundé, Cameroun, Fac Sci. 1991:140 p.

15. Bell A, Ngondombol MT, Kaya MT, Simo $\mathbf{J}$ and $\mathbf{J}$ Tcheudem Etude longitudinale sur l'alimentation complémentaire des nourrissons de Yaoundé (6-23 mois). Revue. Science et Technique1988; 4: 1-5.

16. AOAC. Association of Officials and Analytical Chemists, 13. Washington D.C. 1980.

17. Clegg MS, Keen CL, Lönnerdal B and LS Hurley Influence of ashing techniques on the analysis of trace elements in tissues. Biol. Ttrace Elem. Res.3: 107-115.

18. Wilkinson L (SYSTAT) The system for statistics. Evanston I. L., SYSTAT, Inc. 1990; 1-62.

19. LarteyA, Manu A, Brown KH, Peerson MJ and KG Dewey A rendomized community-based trial of the effects of improved, centrally processed complementary foods on growth and micronutrient status of Ghanaian infants from 6 to 12 mo of age. American Journal of Clinical Nutrition1999; 70: 391404.

20. Onabanjo OO and CRB Oguntona Iron, zinc, copper and phytate content of standardized Nigerian dishes. J. Food Comp. Anal.2003;16 :669-676.

21. FAO/IAEA/WHO. Trace elements in Human nutrition and health.Geneva, World Health Organization.1996.

22. Koenig JS, Marija-Stojaovic $\mathbf{P}$ and IE Shauder Calcium, iron, zinc, copper, manganese and selenium concentrations in typical hospital diets, In: Elmadfa I, Anklam König, J.S. (eds): Modern Aspect of Nutrition, Present knowledge and Futures Perspectives. Forum Nutr: Basel, Karger 2003;56 :56-59. 
23. Rivera J, Brown KH, Hotz $\mathbf{C}$ and $\mathbf{M}$ Ruel Zinc Deficiency: Issues for Public Health, Assessment and Prevention. In: Elmadfa I and Anklam König, J.S. (eds): Modern Aspect of Nutrition, Present Knowledge and Futures Perspectives. Forum Nutr: Basel, Karger. 2003; 56: 59-61.

24. FAO Human Vitamin and Mineral Requirements. Report of a joint FAO/WHO Expert consultation Bangkok, Thailand.Food and Nutrition Division FAO Rome 2001: 257-270.

24. Yonekura $\mathbf{L}$ and $\mathbf{H}$ Susuki Some polysaccharides improve zinc bioavailability in rats fed a phytic acid-containing diet. Nutr. Res, 2003;23: 343-355.

26. Davidsson L Approches to improve iron bioavailability from complementary foods, In: Dietary factors influencing trace element homeostasis published by ASNS (American Society for Nutritional Sciences) 2003: 1560S-1562S.

27. Kana Sop MM Etude de la biodisponibilité du fer et des apports en quelques minéraux des principaux aliments de sevrage camerounais consommés dans trois zones du Cameroun. Thèse de Doctorat de troisième Cycle. Université de Yaoundé I, Fac. Sci. 2000: 202p.

28. Nnyepi MS, Bond J, Johnson $\mathbf{N}$ and $\mathbf{L}$ Weatherspoon Influence of complementary foods on the growth indicators of children in Gabane, Botswana. African J. Food, Agric., Nutr. Develop. ,2004; 4(1): 1684-5376. 